\title{
A CIDADE MÉdIA DE SANTA MARIA E A GESTÃO DO TERRITÓRIO NA REGIÃO CENTRAL-RS-BRASIL
}

Rogério Leandro Lima da Silveira ${ }^{1}$ Carolina Rezende Faccin² Débora Frantz $\mathrm{Krug}^{3}$

Resumo: Aborda-se a centralidade e a capacidade de gestão territorial da cidade média de Santa Maria em sua região de influência, utilizando como recorte a Região Funcional 8 de Planejamento, também conhecida como a Região Central do Estado Rio Grande do Sul. Revisa-se os conceitos de cidade média e gestão territorial e analisa-se os fluxos de gestão pública e de gestão empresarial, bem como seus reflexos na configuração e no funcionamento da rede urbana e dinâmica regional. Utiliza-se os dados secundários do Censo Demográfico (2000 e 2010) e os estudos REGIC (2007 e 2018) e Gestão do Território (2014) do IBGE referentes às formas que o Estado e o Mercado organizam o espaço regional. O conjunto de fluxos de gestão pública e empresarial, no território regional, tem contribuído para aprofundar a urbanização, complexificar as funções urbanas, ampliar a centralidade e o papel de comando da cidade de Santa Maria na região.

Palavras-chave: Cidade média. Gestão territorial. Dinâmica regional.

\section{THE MEDIUM-SIZE CITY OF SANTA MARIA AND THE TERRITORY MANAGEMENT IN THE CENTRAL REGION OF RIO GRANDE DO SUL, BRAZIL}

Abstract: This study addresses the centrality and territorial management capacity of the medium-size city of Santa Maria in its region of influence, using as study scope the Functional Region 8 of Planning, also known as the Central Region of the state of Rio Grande do Sul. It reviews the concepts of medium-size city and territorial management and analyzes the flows of public and business management, as well as their impact on the configuration and functioning of the urban network and regional dynamics. Secondary data from the Demographic Census (2000 and 2010) and the REGIC (2007 e 2018) and Territory Management (2014) studies from IBGE are used regarding to the ways in which the State and the Market organize the regional space. The set of public and business flows of management, in the regional territory, has contributed to deepen urbanization, complexify urban functions, increase the centrality and the role of command of the city of Santa Maria in the region.

Keywords: Medium-size city. Territorial management. Regional dynamics.

\footnotetext{
${ }^{1}$ Universidade de Santa Cruz do Sul, Programa de Pós-Graduação em Desenvolvimento Regional, Santa Cruz do Sul, Brasil. Pesquisador do CNPq. rlls@unisc.br, https://orcid.org/0000-0003-10039470

2 Universidade Federal do Rio Grande do Sul, Programa de Pós-Graduação em Planejamento Urbano e Regional, Porto Alegre, Brasil faccincarolina@gmail.com, https://orcid.org/0000-0003-2850-158X ${ }^{3}$ Universidade de Santa Cruz do Sul, Curso de Arquitetura e Urbanismo, Santa Cruz do Sul, Brasil krugdebora@gmail.com, https://orcid.org/0000-0003-2786-4645
} 


\section{LA CIUDAD INTERMEDIA DE SANTA MARÍA Y LA GESTIÓN DEL TERRITORIO EN LA REGIÓN CENTRAL-RS-BRASIL}

Resumen: Se aborda la centralidad y capacidad de gestión territorial de la ciudad promedio de Santa María en su región de influencia, utilizando la Región Funcional 8 de Planificación, también conocida como la Región Central del Estado de Rio Grande do Sul. Se revisan los conceptos de ciudad media y gestión territorial y se analizan los flujos de gestión pública y empresarial, así como sus reflejos en la configuración y funcionamiento de la red urbana y las dinámicas regionales. Se utilizan datos secundarios del Censo Demográfico (2000 y 2010) y de los estudios REGIC (2007 y 2018) y Gestión del Territorio (2014) del IBGE referentes a las formas en que el Estado y el Mercado organizan el espacio regional. El conjunto de flujos de gestión pública y empresarial, en el territorio regional, ha contribuido a profundizar la urbanización, a complejas funciones urbanas, a ampliar la centralidad y el rol de mando de la ciudad de Santa María en la región.

Palabras clave: Ciudad intermedia. Gestión del territorio. Dinámica regional.

\section{Introdução}

A urbanização mundial tem crescido intensamente nas últimas décadas. Se em 1950, 30\% da população mundial vivia em cidades, em 2014, já eram 54\% da população do planeta vivendo nelas. Número que tende a ampliar para $60 \% \mathrm{em}$ 2030 e para 66\% em 2050 (ONU, 2014).

Nesse contexto, embora ainda haja um predomínio dos estudos sobre o processo de urbanização a partir da análise do fenômeno urbano metropolitano, dada a sua representatividade não apenas pela densidade demográfica como pelos problemas urbanos e ambientais apresentados, têm igualmente ocorrido um crescente interesse de pesquisa sobre o processo de urbanização das cidades médias, sua relação com o espaço regional e com o desenvolvimento territorial, através da sua participação e papel de comando nas redes urbanas regionais.

Sobre esses aspectos, cabe destacar as importantes pesquisas e reflexões teóricas e metodológicas desenvolvidas no Brasil, pela Rede de Pesquisa sobre Cidades Médias (RECIME) coordenada por Maria Encarnação B. Sposito (SPOSITO; SILVA, 2017); na Espanha, por Martínez Navarro, J. M., García González, J. A., e Escudero Gómez, L. A. (2020) e pela Cátedra da UNESCO "Ciudades Intermedias, Urbanización y Desarrollo" (CIMES), coordenada por Carmen Bellet e Josep Maria Llop (BELLET; OLAZABAL, 2020; LLOP; USÓN, 2012); na Argentina, por Lan e Migueltorena (2017); em Portugal, por Eduarda Marques da Costa (2017); na França, por Demazière (2017) e em nível 
internacional, por Roberts (2014) quando aborda a importância das cidades secundárias nos processos de desenvolvimento, apresentando um novo sentido para as cidades médias.

Dentre os muitos aspectos relativos ao processo de urbanização das cidades médias, estão a centralidade e a capacidade de gestão territorial que essas cidades exercem nos espaços geográficos regionais onde estão localizadas. Através das funções administrativas e econômicas, elas se relacionam com sua região de influência, bem como intermediam fluxos de natureza diversa (pessoas, mercadorias, insumos, capitais, informações etc.) que circulam entre as áreas rurais e cidades pequenas, que constituem sua região de influência, e as metrópoles.

Nesse trabalho, abordamos a centralidade e a gestão territorial das cidades médias em seus espaços regionais. O objetivo é de analisar as relações que essas cidades estabelecem com sua região de influência através dos fluxos de gestão pública, advindos da atuação descentralizada do Estado, e dos fluxos de gestão privada, resultantes das estratégias e ações de funcionamento do Mercado no espaço geográfico regional. Abordamos ainda os reflexos de tais fluxos na configuração e dinâmica de funcionamento da rede urbana e no processo de desenvolvimento regional.

O recorte empírico escolhido para a análise é Região Funcional 8 de Planejamento, também conhecida como Região Central, localizada na zona centrooriental do Estado do Rio Grande do Sul, onde se localiza a cidade média de Santa Maria. Tal cidade média desempenha importante papel de centro regional atraindo os deslocamentos pendulares para trabalho e estudo e polarizando através dos fluxos de comércio e de serviços e dos fluxos de gestão, amplo espaço geográfico no contexto do território regional.

Em termos metodológicos se utilizou os estudos e as contribuições de Maturana, Sposito, Bellet, Henríquez e Arenas (2017), de Sposito e Silva (2017), de Stamm, Wadi e Staduto (2010) e de Silveira et al. (2017) na abordagem e análise das cidades médias e sua relação com o desenvolvimento regional, e os aportes de Corrêa (2018), Servillo et al. (2014) e Neal (2013) sobre redes urbanas e sua relação com o desenvolvimento e coesão territorial. Os dados secundários utilizados na análise foram levantados através do Censo Demográfico (2010), e dos estudos Região de Influência das Cidades - REGIC 2007 e 2018 e Gestão do Território (2014), todos realizados pelo Instituto Brasileiro de Geografia e Estatística (IBGE) e do repositório Infraestrutura Estadual de Dados Espaciais (IEDE) do Rio Grande do 
Sul. Priorizou-se a coleta de dados relativos à população total e urbana, e aos fluxos de gestão do território, pública e privada. Após o levantamento e organização dos dados em planilhas eletrônicas, eles foram tratados e analisados através da confecção de gráficos, tabelas e mapas temáticos, com a utilização dos softwares Excel, QGIS e Adobe Illustrator.

O artigo, além desta introdução, está constituído por outros três tópicos. Num primeiro, apresentamos o que estamos entendendo por gestão territorial e cidade média, a relação da cidade média com a região e com a rede urbana, e como elas desenvolvem sua gestão territorial através dos fluxos de gestão pública e privada. No segundo tópico, realizamos uma breve e sintética caracterização socioespacial da Região Funcional 8 de Planejamento no Rio Grande do Sul, da cidade média de Santa Maria e da rede urbana regional. Por fim, no terceiro tópico, analisamos as principais características da gestão do território realizado pela cidade de Santa Maria, e sua relação com o desenvolvimento territorial e com a rede urbana regional. Para tanto, analisamos os dados relativos aos fluxos de gestão pública e de gestão empresarial, respectivamente comandados, e realizados ou atraídos por essa cidade média no espaço regional, e sua relação com a dinâmica territorial.

\section{Cidades médias e gestão do território}

O conceito e a definição de cidade média estão em construção. Não há uma definição consensual a respeito, dada a especificidade e diversidade da classificação e tipologia urbana empregada em cada país. Ora vamos ter a sua definição baseada no critério demográfico, ora pela centralidade e funções urbanas das cidades (SPOSITO; SILVA, 2017; SPOSITO, 2018). Além disso, os critérios utilizados para sua definição dependem dos objetivos dos especialistas na análise e implementação das políticas públicas específicas (BELLET et al., 2015; MOTTA; MATA, 2008).

De todo modo, pensamos que sua definição não deva estar apenas vinculada ao tamanho da sua população, como faz o IBGE ao classificar como média as cidades que apresentam entre 100 e 500 mil habitantes. Embora o tamanho demográfico seja um dado importante a ser considerado, a definição de cidade média deve também estar vinculada ao papel, à função que a cidade desempenha regionalmente, exercendo forte relação com a região na qual está localizada. 
A noção de cidade média que pensamos mais adequada, e que utilizamos neste trabalho, é a que corresponde às cidades que além de possuírem um contingente demográfico expressivo, no contexto regional, também apresentam uma concentração e centralização econômicas e uma consolidada função de intermediação econômica e de serviços públicos, e de fluxos diversos, entre sua hinterlândia e a metrópole. Além disso é preciso também considerar os níveis das atividades econômicas resultantes da confluência dos sistemas de transporte e logística, e a reconfiguração espacial advinda da incorporação de novas atividades ao setor agropecuário que, por sua vez, redefinem a indústria, o comércio e os serviços, e as funções e centralidade urbana das cidades médias (SPOSITO, 2018; VARGAS, 2020; SCHERER; AMARAL, 2020; SANTOS; SILVEIRA, 2001; OLIVEIRA; SOARES, 2014).

Por sua vez, adotamos aqui o conceito de gestão do território como propõe Corrêa (1992, p. 35). Ela "constitui-se em uma faceta da gestão econômica, política e social, a ela estando subordinada, mas também a condicionando. É a dimensão espacial do processo geral de gestão, confinando-se ao espaço sob controle de um Estado ou de uma dada empresa".

As cidades, como centros de organização da vida social, em suas dimensões econômicas e políticas, e espaços de concentração da população e das atividades produtivas e de serviços públicos e privados, se constituem em unidades de referência no território, nas e a partir das quais, diferentes estratégias e ações de gestão são acionadas tanto pelo Estado como pelo Mercado. Estes buscam garantir sua reprodução, através de uma dada organização espacial dos seus fixos, ou objetos geográficos, e de seus fluxos ou ações, em uma perspectiva multiescalar: combinando simultaneamente e de modo desigual, ações de gestão nas escalas do município, da região, do país, e do espaço global.

Assim como as metrópoles desempenham destacado papel na gestão do território na escala mundial, as cidades médias igualmente apresentam relevante atuação na gestão territorial, notadamente na escala regional onde estão inseridas espacialmente e onde atuam, através da função de intermediação de fluxos de naturezas diversas (ROBERTS, 2014; IGLESIAS, 2016).

Os processos de gestão territorial que as cidades médias centralizam e através dos quais exercem influência regional, estão vinculados ao controle que o Estado, através da sua organização e da gestão de serviços públicos, estabelece no/do espaço. Igualmente têm importância para a gestão territorial das cidades 
médias, as ações e estratégias de organização, controle e de uso espacial, coordenadas pelos grupos empresariais, através das suas sedes instaladas nessas cidades, ou das suas filiais atraídas por aquelas cidades. Ações e estratégias que possuem como objetivo o controle da organização do espaço, ou seja, "a criação e controle das formas espaciais, suas funções e distribuição espacial, assim como determinados processos como concentração e dispersão espaciais, que conformam a organização do espaço em suas origens e dinâmicas" (CORRÊA, 1992, p. 35).

O Estado é um relevante agente produtor e organizador do espaço, através tanto de sua atuação econômica quanto promovendo políticas públicas setoriais diversas, buscando, através de sua estrutura e serviços, atender a população, estar presente no território, levantar informações e organizar os recursos públicos. As instituições públicas, que viabilizam a ação do Estado, geralmente se organizam espacialmente de modo multilocalizadas com diversas instalações e repartições no território brasileiro, apresentando uma estrutura hierárquica interna que reflete um dado modo de gestão do território pelo Estado, através de suas diversas instâncias administrativas a maneira pela qual o território é gerido (IBGE, 2014; MARQUES; RIBEIRO, 2019).

A configuração espacial e a intensidade das ligações econômicas entre as empresas são variáveis importantes para a análise dos padrões das redes de gestão territorial, bem como para gerar uma dada medida da centralidade urbana no espaço regional. Assim, a intensidade das ligações resulta do somatório das interações entre as empresas sedes e suas filiais, considerando a capacidade de cada município em abrigar empresas-sedes locais que se articulam com sucursais externas ao seu território e, ao mesmo tempo, levando em conta a presença de filiais atraídas para o seu território, sendo estas geridas por empresas-sede instaladas fora dos seus limites (IBGE, 2014).

A gestão do território, focalizada em centros urbanos, a partir de organizações descentralizadas e corporações multifacetadas e com múltiplas localizações, é o meio através do qual é viabilizada a criação e a manutenção de diferenças econômicas e sociais no âmbito dos espaços regionais. Os papéis e as funções desempenhadas pelas cidades médias no contexto de organização e funcionamento da rede urbana regional, através dos fluxos de gestão territorial, se apresentam como dimensões fundamentais para análise da dinâmica do desenvolvimento territorial. 
No Brasil, praticamente ainda inexistem estudos de caso sobre a gestão pública e privada no território por organizações e empresas localizadas ou atuando em cidades médias brasileiras. O que temos são os estudos mais gerais sobre esse tema no contexto da rede urbana brasileira realizados pelo IBGE, para o conjunto do território brasileiro, em IBGE (2007, 2014 e 2018) e os estudos clássicos e seminais de Corrêa (1989, 1992 e 1996), estabelecendo os pressupostos teóricos e os percursos metodológicos para a pesquisa sobre a gestão territorial.

Nesse sentindo, busca-se no presente artigo contribuir com o avanço da reflexão teórica e metodológica sobre essa temática, desde a especificidade das cidades médias analisando como tais processos têm se apresentado na cidade média de Santa Maria através da centralização dos fluxos de gestão pública e privada que a cidade média de Santa Maria apresenta na região Central do Rio Grande do Sul, mais especificamente, na Região Funcional 8 de Planejamento.

\section{A Região Funcional 8 de Planejamento e a cidade média de Santa Maria}

A Região Funcional 8 de Planejamento está localizada no centro ocidente do estado do Rio Grande do Sul, e é composta por quatro COREDEs: Alto Jacuí, Central, Jacuí Centro e Vale do Jaguari. É constituída de 49 municípios, sendo 19 deles no COREDE Central, onde localiza-se a cidade média de Santa Maria, polo econômico de toda a Região (Figura 1). Essa ampla região se caracteriza pela predominância da atividade agropecuária, com destaque para a produção e beneficiamento industrial do arroz, do trigo e da soja, além da criação de gado bovino. A região é polarizada pela cidade média de Santa Maria, capital regional $C$ de acordo com a REGIC - 2018 (IBGE, 2020). A delimitação territorial da Região Funcional 8 é convergente com a regionalização urbano regional do IBGE (2013) que identifica nesse território a Região Imediata de Articulação Urbana de Santa Maria, na qual a cidade média de Santa Maria desempenha o papel de comando regional. 
Figura 1 - Localização da Região Funcional 8 de Planejamento - RS

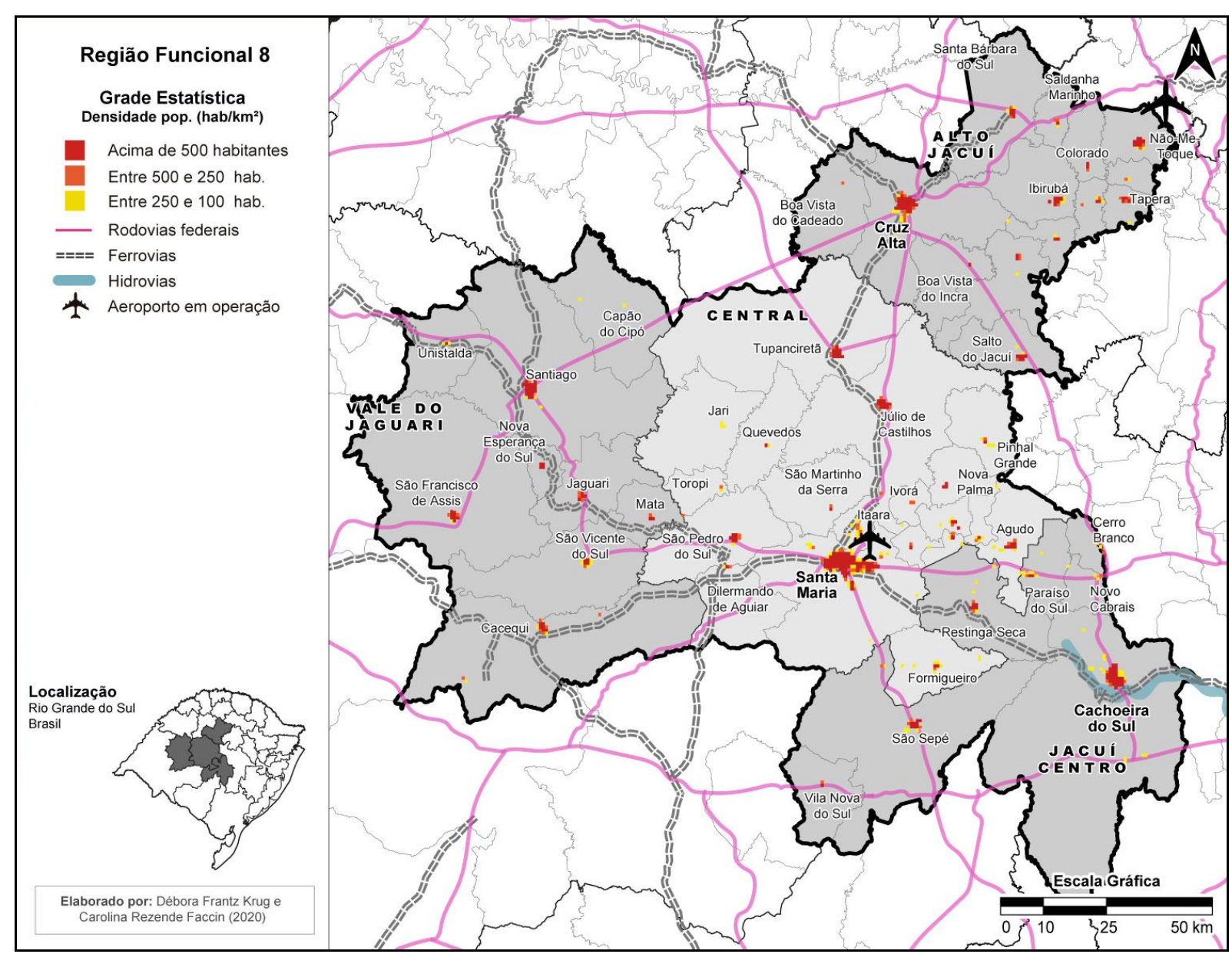

Fonte: IBGE (2016). Elaborada pelas autoras: Débora Frantz Krug e Carolina Rezende Faccin.

A configuração espacial da região evidencia que há pelo menos dois conjuntos de municípios quanto a dimensão territorial, resultantes de diferenciadas estruturas fundiárias. De um lado, há os municípios ao norte, que integram a região do COREDE Alto Jacuí, que apresentam pequena área territorial fruto de um intenso processo de fragmentação e parcelamento de propriedades rurais, advindos da busca de reprodução social pelas sucessivas gerações das famílias que colonizaram essa região, bem como resultam do processo de emancipações municipais que ocorreram sobretudo a partir dos anos 1980 (SPGG, 2017).

De outro lado, no centro e no sul da região, nos COREDEs: Central, Vale do Jaguari e Jacuí Centro há um predomínio dos municípios com médias e grandes áreas territoriais, advindas de uma estrutura fundiária caracterizada pela média e grande propriedade. Esta última, característica predominante na metade sul do RS desde os tempos coloniais.

Santa Maria é a cidade com maior contingente demográfico, com expressiva centralidade urbana, através de uma economia urbana baseada sobretudo nas 
atividades comerciais e serviços, e que polariza e influencia o conjunto da região. De acordo com a estimativa populacional do IBGE (2020), o município de Santa Maria apresentava 283.677 habitantes em 2019.

A centralidade de Santa Maria também é exercida através da oferta de ensino superior através da Universidade Federal de Santa Maria - UFSM, bem como de outras universidades e faculdades nela sediadas. Uma outra atividade que reforça essa centralidade é a militar, através da existência na cidade de inúmeras instalações do exército e da aeronáutica. Na região também se destacam as cidades de Cruz Alta e Cachoeira do Sul, importantes centros sub-regionais que polarizam suas regiões imediatas. Cruz Alta, importante centro urbano localizado na região do Alto Jacuí se caracteriza por apresentar uma economia urbana articulada e de apoio à produção agroindustrial da soja e do trigo. Cachoeira do Sul, por sua vez polariza a região Jacuí Centro, caracterizada pela agroindústria do arroz e criação de gado.

Outro aspecto a ser destacado na configuração territorial e urbana da região é sua estrutura urbana. Com base na tabela 1, observa-se que há o predomínio de pequenas cidades (30 de 49) com até 5 mil habitantes. Elas representam $61,22 \%$ do total das cidades da rede urbana regional. Apenas a cidade média de Santa Maria possui mais de 100 mil habitantes (248 mil) e as cidades de Cruz Alta (60 mil) e Cachoeira do Sul (70 mil) integram o escalão de 50 a 100 mil habitantes (IBGE, 2010).

Tabela 1 - Estrutura da rede urbana da Região Funcional 8: № de cidades por faixa de população urbana (2010).

\begin{tabular}{|c|c|c|c|c|c|}
\hline $\begin{array}{c}\text { Até } 5 \text { mil } \\
\text { habitantes. }\end{array}$ & $\begin{array}{c}\text { De } 5.001 \mathrm{a} \\
10.000 \mathrm{hab} .\end{array}$ & $\begin{array}{c}10.001 \mathrm{a} \\
20.000 \text { hab. }\end{array}$ & $\begin{array}{c}20.001 \mathrm{a} \\
50.000 \mathrm{hab} .\end{array}$ & $\begin{array}{c}50.001 \text { a } \\
100.000 \text { hab. }\end{array}$ & $\begin{array}{c}\text { Mais de } \\
100.001 \text { hab. }\end{array}$ \\
\hline 30 & 7 & 8 & 1 & 2 & 1 \\
\hline
\end{tabular}

Os dados acima mostram que a estrutura urbana regional evidencia uma distribuição desigual da população urbana entre as cidades da região. Mostram ainda que há uma concentração em três cidades do território, sobretudo em Santa Maria, e secundariamente em Cruz Alta e Cachoeira do Sul, da população urbana regional. A maior centralidade e dinamismo econômico de tais cidades atrai a população regional e concentra a maior parte dos fluxos que anima a rede urbana regional.

Em relação aos aspectos demográficos, a região, em 2010, possuía uma população de 807.487 habitantes, correspondendo a $7 \%$ da população gaúcha. No 
conjunto da população regional 81\% residem na área urbana, e 19\% na área rural. Entre 2000 e 2010, a Região apresentou uma taxa de crescimento demográfico inexpressiva de 0,01\% ao ano (IBGE, 2010).

Dos quatro COREDEs que integram a Região Funcional, somente o Central, com taxa de $0,37 \%$, teve crescimento demográfico positivo. Os restantes COREDEs apresentaram taxas negativas. No COREDE Central, o destaque é para o município de Itaara, com 0,91\%, e de Santa Maria, com 0,69\%, que apresentam os maiores valores de crescimento. Dos 49 municípios da Região Funcional, 18 deles possuem a maior parte da população residindo na área rural, com taxas de urbanização inferior a 50\%, refletindo a predominância nestes municípios das pequenas e médias propriedades agrícolas, com a presença da agricultura familiar e do agronegócio. Nesses municípios temos pequenas cidades que exercem basicamente a função de gestão municipal e centros de escoamento da produção agrícola local, com limitada oferta dos serviços básicos e capacidade de geração de emprego (IBGE, 2010).

Os municípios com maior taxa de urbanização são: no COREDE Alto Jacuí, as cidades de Cruz Alta, com 96,5\% e de Não-me-Toque com 87,6\% da sua população total residindo nas áreas urbanas. Já no COREDE Central, destacam-se as cidades de Santa Maria com 95,1\% e Júlio de Castilhos com 82,3\%. No COREDE Jacuí-Centro é a cidade de Cachoeira do Sul com 85,5\% aquela com maior taxa de urbanização. Por fim, no COREDE do Vale do Jaguari, se destacam as cidades de Santiago com 91,2\% e Cacequi $87,4 \%$ (IBGE, 2010).

$\mathrm{Na}$ Tabela 2 observamos o quão representativo, em termos demográficos, em relação à população total e população urbana, é o município de Santa Maria em relação ao total da população urbana e total da Região Funcional 8 - a cidade corresponde a $44 \%$ da população urbana da região.

Tabela 2 - Região Funcional 8 e Santa Maria: População urbana, população total e taxa de urbanização - 2000 e 2010

\begin{tabular}{lcccccc}
\hline & \multicolumn{2}{c}{ População urbana } & \multicolumn{2}{c}{ População total } & \multicolumn{2}{c}{ Taxa de urbanização } \\
Municípios & $\mathbf{2 0 0 0}$ & $\mathbf{2 0 1 0}$ & $\mathbf{2 0 0 0}$ & $\mathbf{2 0 1 0}$ & $\mathbf{2 0 0 0}$ & $\mathbf{2 0 1 0}$ \\
\hline Santa Maria & 230.696 & 248.347 & 243.611 & 261.031 & $94,7 \%$ & $95,1 \%$ \\
Demais municípios & 504.451 & 314.600 & 718.380 & 546.456 & $69,7 \%$ & $73,3 \%$ \\
Região Funcional 8 & 735.147 & 562.947 & 961.991 & 807.487 & $76,4 \%$ & $69,7 \%$ \\
Rio Grande do Sul & 8.317 .984 & 9.100 .291 & 10.187 .798 & 10.693 .929 & $81,6 \%$ & $85,1 \%$ \\
\hline Fonte: IBGE (2010). Elaborada & pelos autores: Nicolas & Billig de Giacometti e Carolina Rezende \\
Faccin. & & & & & \multicolumn{2}{c}{ R }
\end{tabular}

Verificamos ainda que a cidade média de Santa Maria apresenta ampliação do processo de urbanização entre 2000 e 2010, de 94,70\% para 95,14\%, 
consolidando sua posição de centro urbano mais populoso da Região Funcional 8 (IBGE, 2010).

Em relação à economia regional assinala-se que o Produto Interno Bruto em 2012 foi de $\mathrm{R} \$ 16,7$ bilhões, correspondendo a $6 \%$ do PIB total gaúcho. "Os COREDEs Central e Alto Jacuí somaram conjuntamente $75 \%$ desse total, com $44 \%$ e $31 \%$, respectivamente. Destaque para o COREDE Alto Jacuí, que possuía, neste ano, o segundo maior PIB per capita do Estado. Os municípios de Santa Maria, Cruz Alta e Cachoeira do Sul são os que possuem os maiores valores de PIB na região" (SEPLAG; DEPLAN, 2015, p. 63).

$\mathrm{Na}$ análise da SEPLAG e DEPLAN (2015, p. 65) observa-se ainda que a RF8 possui como traço comum o fato de que uma grande parte da produção econômica tem origem na atividade agropecuária. Essa atividade é diversificada e está relacionada com o processo de ocupação territorial e com a localização geográfica, que compreende distintos compartimentos geomorfológicos e tipos de solo. Como resultado, tem-se a presença de grandes e médias propriedades, ocupadas por lavoura empresarial de arroz e soja; pequenas propriedades de origem colonial com produção diversificada; e áreas de pastagens, onde se desenvolve a pecuária. $\mathrm{O}$ cultivo da soja possui destaque na região, que é responsável por $24,5 \%$ do valor da produção da soja em grão no Estado.

Complementarmente, os dados da distribuição do VAB setorial nos municípios do conjunto da Região Funcional 8 (IBGE, 2010), indicam que para muitos municípios há uma grande dependência econômica dos recursos advindos da dos setores de comércio e serviços e da administração pública, no qual estão os repasses constitucionais (Fundo de Participação dos Municípios) e os recursos relativos à aposentadorias rurais e urbanas, Benefício de Prestação Continuada, Bolsa Família entre outros. Também é muito representativo na economia de muitos municípios os recursos advindos das atividades agropecuárias, reforçando a importância da agricultura familiar, mas também dos cultivos agroindustriais, como é o caso da soja, do trigo e do arroz.

$\mathrm{Na}$ cidade média de Santa Maria há uma grande dependência do setor de comércio e de serviços, com destaque para a presença de redes de atacados, estabelecimentos comerciais e cadeias de supermercado. Também merece destaque os serviços públicos de educação e saúde, e administrativos vinculados aos governos estadual e federal, que a cidade sedia. 
Em relação a distribuição do número de empresas na região, observa-se no Gráfico 1 e na Figura 2, que em 2010, Santa Maria respondia por 5.929 empresas, representando $38,45 \%$ do total das empresas existentes na região funcional. Em segundo lugar, aparece Cachoeira do Sul, com 1.842 empresas (11,9\%) e a seguir Cruz Alta, com 1.413 empresas (9,2\%). Os dados explicitam a forte centralidade da economia urbana de Santa Maria (IBGE, 2018).

Gráfico 1 - Número total de empresas nos municípios da Região Funcional 08 -

2010

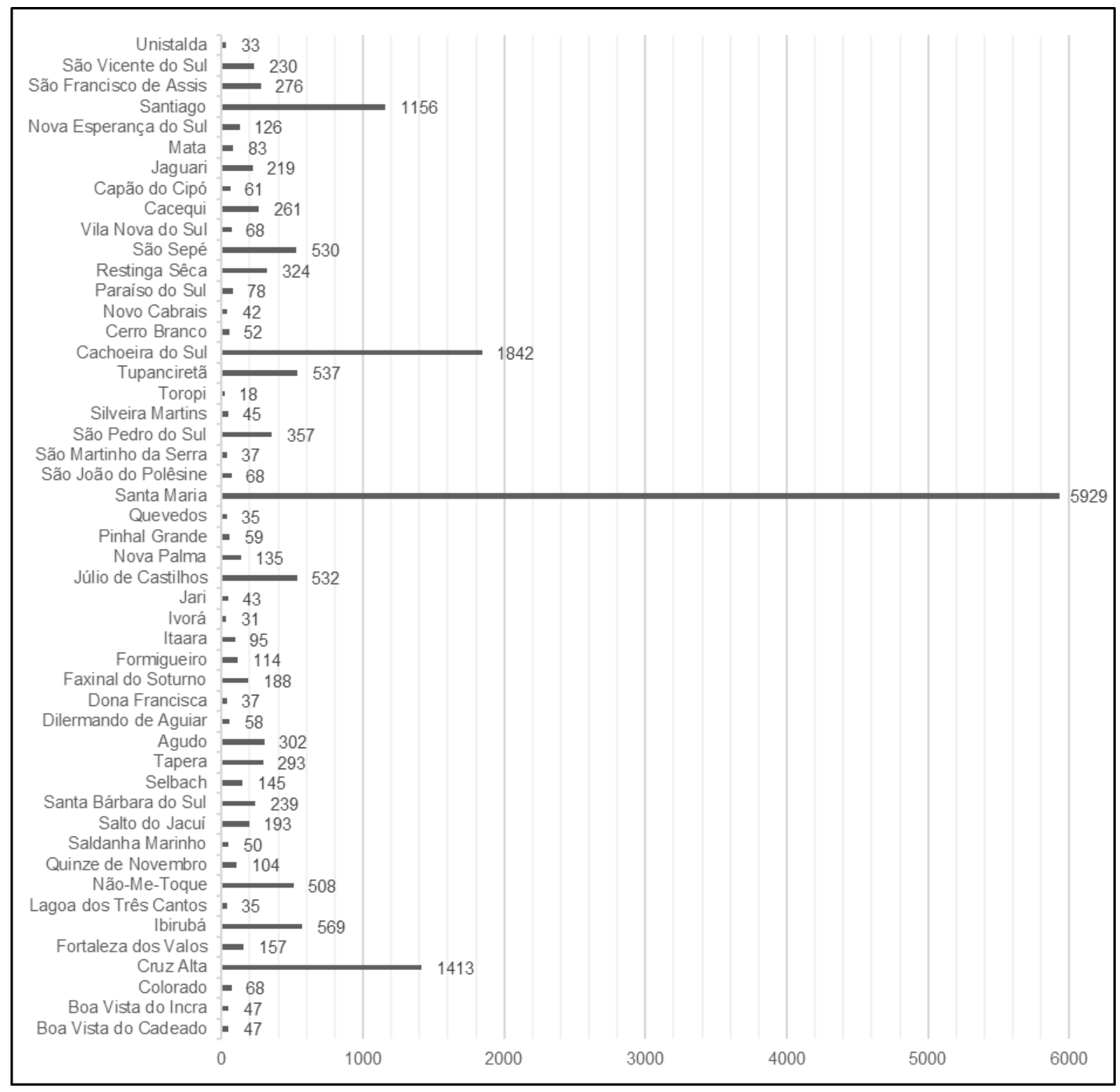

Fonte: Pesquisa de Informações Básicas Municipais - MUNIC (IBGE, 2018). Elaborado pelo autor: Rogério Leandro Lima da Silveira.

Além de responder pelo maior número de empresas existentes na região a economia urbana de Santa Maria estrutura sua centralidade e funções econômicas no território regional através principalmente das atividades ofertadas pelos 
estabelecimentos comerciais atacadistas e varejistas e de serviços. Também se destacam embora com menor intensidade as empresas industriais de transformação e de construção civil (Figura 2).

Figura 2 - Região Funcional 08: Número e o percentual das empresas, por município, por setores econômicos.

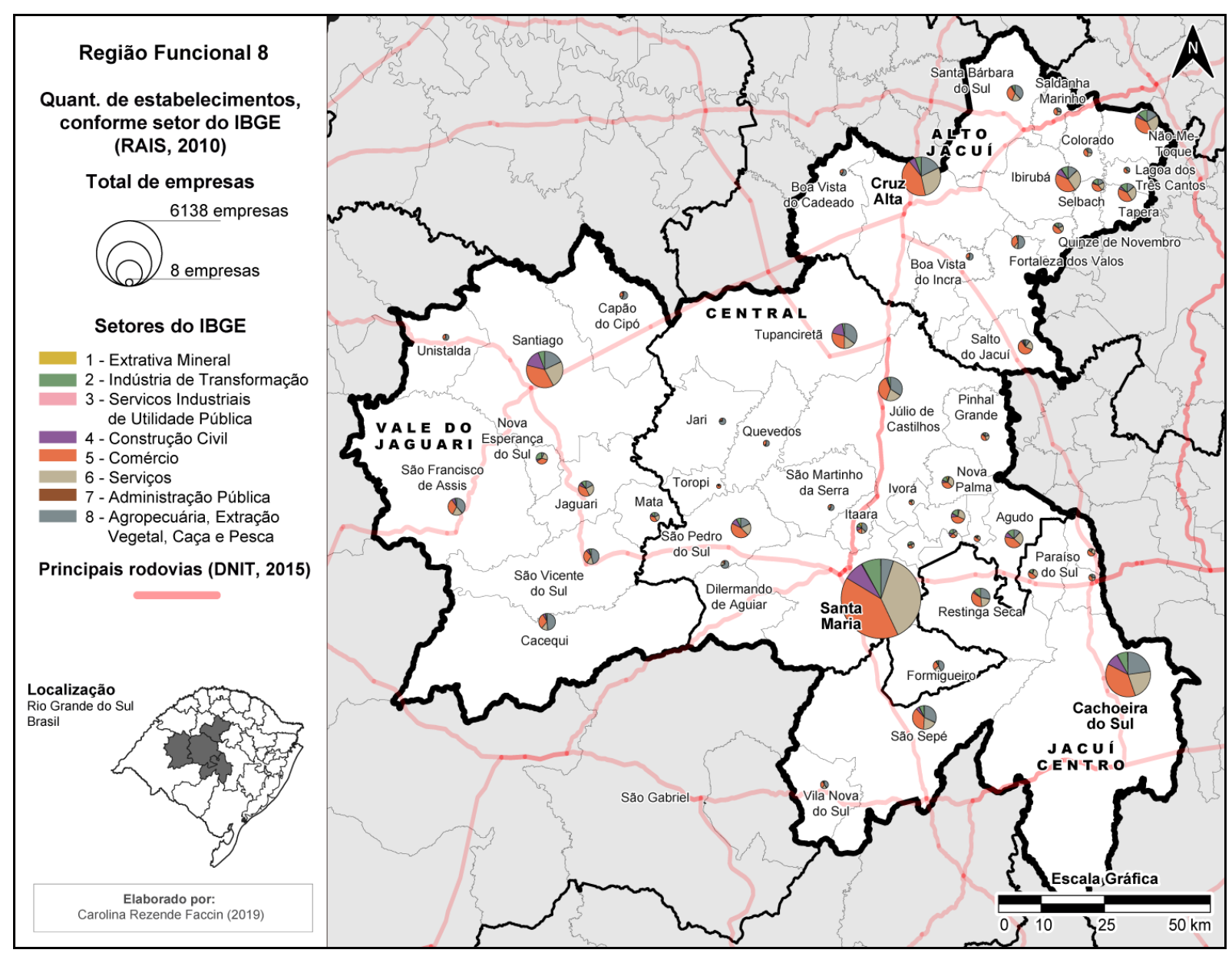

Fonte: RAIS (2010). Elaborada pela autora: Carolina Rezende Faccin.

Quanto aos indicadores sociais, o conjunto dos quatro COREDEs que constituem a Região Funcional de Planejamento 8, apresentavam, em 2012, um Índice de Desenvolvimento Socioeconômico na faixa de médio desenvolvimento $(0,600$ a 0,799$)$. O COREDE Alto Jacuí com IDESE 0,768 , detém o maior valor, ocupando o 6ำ lugar no ranking estadual. Já o Vale do Jaguari possui o menor índice, com valor de 0,689. Analisando os índices municipais, a região possui 04 municípios com IDESE na faixa de alto desenvolvimento, com valores superiores a 0,800. Estão localizados todos no COREDE Alto Jacuí (Não-Me-Toque, Ibirubá, Lagoa dos Três Cantos e Colorado). Os demais municípios estão situados na faixa de médio desenvolvimento, com valores variando de 0,601 em Mata até 0,792 em Selbach (SEPLAG; DEPLAN, 2015). 


\section{Os fluxos de gestão do território na Região Funcional 8 de Planejamento - RS}

Para efetivar a gestão pública do território, o Estado, através dessas instituições públicas, localizadas em diferentes cidades, dissemina ordens, informações e decisões, presta serviços diversos, promove a justiça, bem como, atende demandas, recolhe tributos e levanta dados sobre a realidade do País, desde diferentes lugares, buscando manter o equilíbrio federativo. A organização e a distribuição espacial das instituições públicas "é um fato gerador de centralidade urbana", pois a sua presença numa dada cidade "é capaz de atrair a população dispersa que vem utilizar os serviços que o Estado oferece, ao mesmo tempo em que essas entidades funcionam como núcleos de tomada de decisão, acumulando poder sobre uma porção do território" (IBGE, 2014, p. 25).

Por sua vez, os fluxos de gestão empresarial, advindos da dinâmica de organização e funcionamento do mercado, através das relações entre empresas produtoras, fornecedoras, instituições financeiras, e empresas de logística, bem como através das relações entre as sedes das empresas e as suas filiais, no espaço, são também fonte de geração de centralidade urbana. A sua localização é seletiva e desigual no espaço, bem como são desiguais os fluxos que articulam esses diferentes agentes privados econômicos e públicos no processo de desenvolvimento.

\section{Os fluxos de gestão pública federal e as estruturas de gestão estadual na Região Funcional 8}

Os dados sobre os fluxos de gestão pública federal do território, através da oferta descentralizada de serviços públicos relacionados à Receita Federal, Polícia Federal Previdência Social e Justiça Federal, revelam em destaque a grande centralidade da cidade de Santa Maria no interior da região central, pois é nessa cidade que estão localizadas as repartições desses órgãos públicos que atuam na região. Num segundo escalão, as cidades de Cruz Alta e Cachoeira do Sul também apresentam importante centralidade em relação a oferta de serviços públicos federais nos respectivos territórios dos COREDES, que se apresentam como suas regiões de influência. Os dados mostram também as respectivas áreas de influência imediata de cada cidade, e de outro, a existência de fluxos e ligações cruzadas, 
entre ambas, dada a especialização e a oferta de serviços púbicos federais diferenciados que cada uma das cidades apresenta (Figura 3).

Figura 3 - Fluxos de Gestão Pública Federal e estabelecimentos de gestão pública estadual na Região Funcional 08 de Planejamento

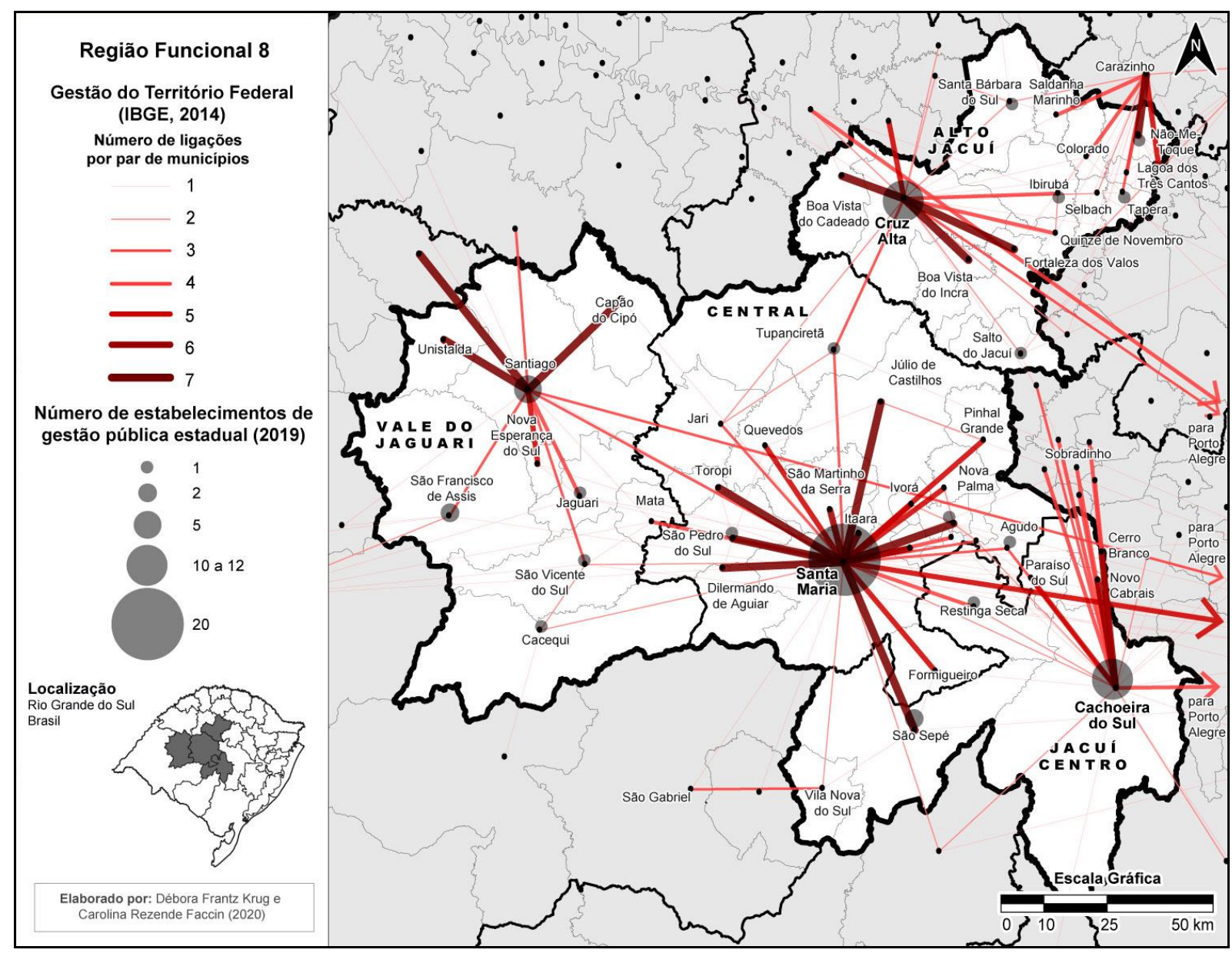

Fonte: IBGE (2014) e IEDE (2019). Elaborada pelas autoras: Débora Frantz Krug e Carolina Rezende Faccin.

Os dados da Figura 3 evidenciam também que Santa Maria centraliza a maior parte dos fluxos de gestão pública federal, bem como aqueles mais intensos, que circulam na Região Funcional 8 de Planejamento, notadamente na sub-região do COREDE Central. Destaca-se a expressiva quantidade de ligações (entre 05 e 07 ligações) que ocorrem entre pares de cidade, evidenciando a diversidade dos fluxos de gestão pública existentes entre a cidade de Santa Maria e cidades como as de: Itaara, Silveira Martins, São Martinho da Serra, Toropi, São Sepé, São Pedro do Sul, Júlio de Castilhos, Faxinal do Soturno, Dilermando de Aguiar, Quevedos, Pinhal Grande, Nova Palma, Ivorá e Formigueiro (IBGE, 2014).

Como centros urbanos secundários em relação à gestão pública do território, temos na Região Funcional 8, a cidade Cruz Alta, que exerce centralidade no âmbito 
intrarregional, notadamente na sub-região do COREDE do Alto Jacuí estabelecendo relações (5 a 6 ligações) principalmente com as cidades de Boa Vista do Cadeado, Boa Vista do Incra, Pejuçara e Fortaleza dos Valos. Outra cidade que se destaca na gestão pública do território na região é a cidade de Cachoeira do Sul, na sub-região do COREDE Jacuí Centro, que centraliza parte dos fluxos de gestão na sua região de influência imediata, com destaque para as ligações mais intensas (entre 5 e 7 ligações) que estabelece com cada uma das cidades de: Novos Cabrais, Cerro Branco e Paraíso do Sul (Figura 3) (IBGE, 2014).

Cabe também destacar as relações que Santa Maria mantém com Porto Alegre, capital do Estado, em razão da localização nesta, das unidades administrativas hierarquicamente superiores, no âmbito da estrutura de gestão descentralizada dos órgãos públicos federais que atuam no Rio Grande do Sul. São exemplos disso, a Justiça federal, INSS, Polícia Federal e a Receita Federal.

A centralidade de Santa Maria em relação aos fluxos de gestão pública territorial se expressa através das atividades desenvolvidas nos setores de Administração Pública, Defesa e Seguridade Social. Nesses setores, a existência na cidade de Santa Maria de inúmeras sedes regionais de órgãos públicos e autarquias federais e estaduais ligadas à agricultura, à saúde, à justiça, à Receita Federal, Seguridade, além da presença de inúmeras estruturas militares das forças armadas (quartéis do exército e base aérea da aeronáutica) dão a ela grande centralidade regional em relação à prestação desses serviços.

Um outro conjunto de serviços públicos que contribuem para essa polarização de Santa Maria são os vinculados ao Setor de Saúde Humana e Serviços Sociais, cuja oferta de serviços de saúde pública e de assistência social, nos hospitais de referência e clínicas especializadas de saúde existentes na cidade presta serviço não apenas para a população municipal, mas também para a população regional região.

Por fim, também se destaca a centralidade regional exercida por Santa Maria através das atividades e serviços desenvolvidos no Setor de Educação, Ciência e Tecnologia através de instituições de ensino e pesquisa que ofertam ensino superior e ensino médio. Temos em Santa Maria a existência de inúmeras Faculdades, Institutos Técnicos e Universidades, com destaque para a Universidade Federal de Santa Maria que em seus 262 cursos ofertados reúne 28 mil alunos, atendidos por 2.310 docentes e 2.689 técnicos administrativos (UFSM, 2020). 


\section{Os fluxos de gestão empresarial na Região Funcional 8}

A cidade de Santa Maria comanda as relações com as demais cidades e municípios da região central através dos fluxos de gestão empresarial (Figura 4). Santa Maria, em razão de sua dinâmica econômica e funções urbanas apresenta forte centralidade regional e desempenha importante papel de comando na rede urbana regional.

Santa Maria se caracteriza como importante polo regional concentrando a oferta da maior parte dos empregos nos setores da indústria (com destaque para os ramos de máquinas e implementos agrícolas, rações, refrigerantes, materiais de construção, equipamentos de energia e telecomunicações) e, principalmente, nos de comércio e serviços existentes na região, cujos principais ramos de atividade instalados nesta cidade média, são logística, transportes, veículos, materiais de construção, atacado e varejo de alimentos, educação superior, saúde, administração pública e defesa.

Figura 4 - Fluxos de gestão empresarial na Região Funcional 08 de Planejamento 2014

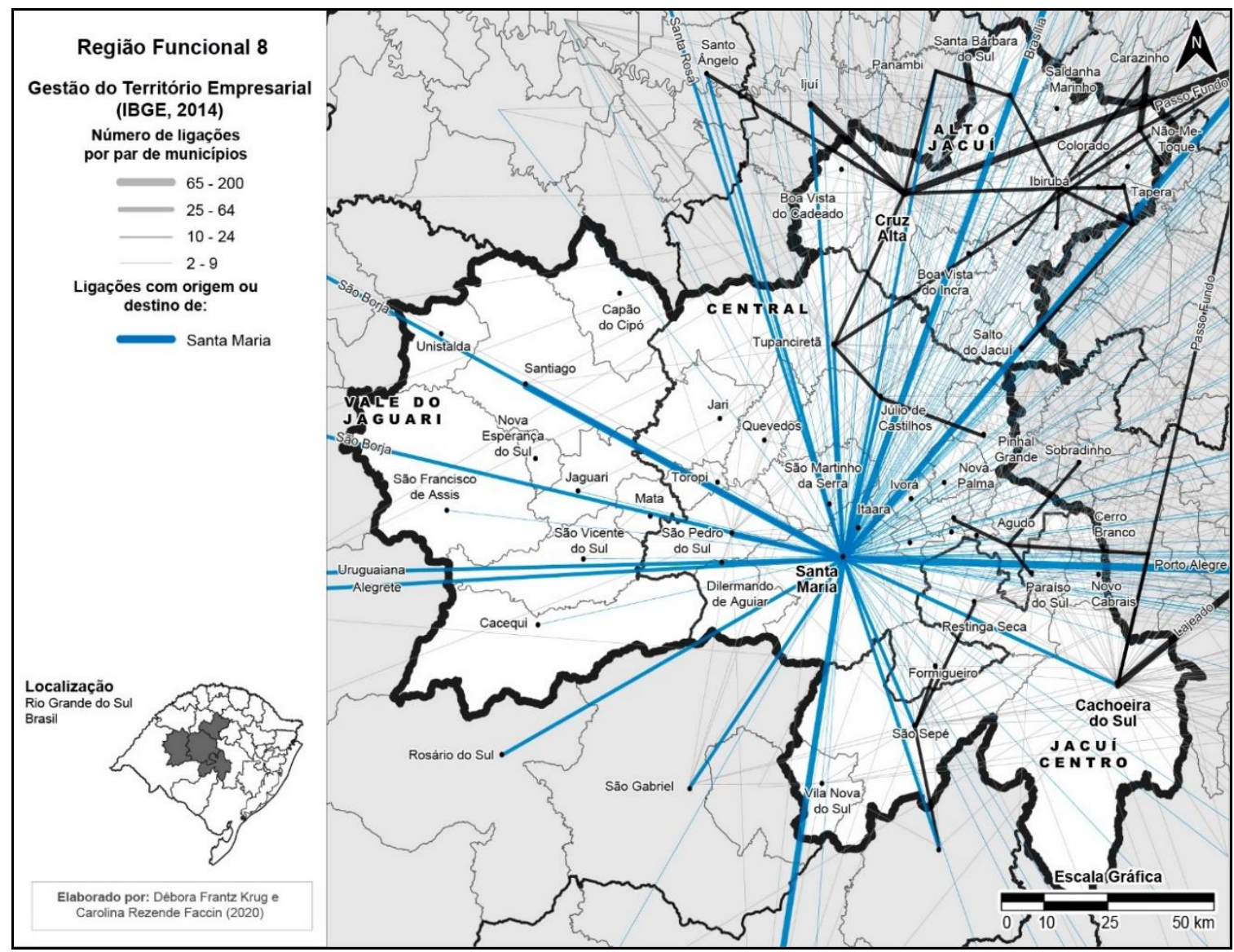

Fonte: IBGE (2014) e IEDE (2019). Elaborada pelas autoras: Débora Frantz Krug e Carolina Rezende Faccin. 
A acessibilidade e a proximidade espacial entre os municípios e cidades que de onde os fluxos se originam e a cidade de Santa Maria que é o centro econômico dessa região, são também variáveis relevantes que contribuem para essa centralidade da cidade média, e que também explicam essa dinâmica espacial no interior do território regional. De um lado, a cidade de Santa Maria intermedia grande parte dos fluxos econômicos e de serviços que se originam na região metropolitana de Porto Alegre e em centros urbanos nacionais que participam das atividades agroindustriais do arroz, da soja, e da mineração de areia, e principalmente das atividades ligadas ao comércio varejista e atacadista que alcançam o conjunto da Região Funcional 8. De outro lado, ela intermedia os fluxos da produção primária e do excedente econômico oriundo das áreas rurais e das pequenas cidades da região que se destinam a essa cidade, ou ao mercado estadual e nacional.

Observando-se a Figura 4, verifica-se que as empresas de Santa Maria estabelecem sua gestão territorial tendo como espaço de atuação preferencial o conjunto do território da Região Funcional 8 de Planejamento, bem como estabelecem relações econômicas intensas com outras cidades localizadas em outras regiões do estado, como são os casos de Santa Cruz do Sul no leste, de Bagé e Pelotas no Sul, e de Santo Ângelo e Passo Fundo no norte do estado. Também se evidencia nos fluxos de gestão empresarial que conectam a cidade de Santa Maria, intensa relação com as metrópoles de Porto Alegre e São Paulo.

Avançando na análise dos fluxos de gestão empresarial existentes no território da Região Funcional 8, a Tabela 3 nos possibilita verificar melhor a dimensão espacial e a dinâmica e intensidade desigual com que as empresas localizadas nas cidades da região estabelecem suas ações de gestão territorial no âmbito da região e do Estado do Rio Grande do Sul. Desse modo, configurando, a efetiva região de influência da cidade média de Santa Maria, através da variável gestão empresarial, nas escalas regional e estadual.

Tabela 3 - Gestão territorial empresarial na RF 8 - 2014: Empresas controladoras, filiais e municípios controlados

\begin{tabular}{lccccc}
\hline Nome do & $\begin{array}{c}\text { Municípios } \\
\text { controlado } \\
\text { município }\end{array}$ & $\begin{array}{c}\text { Empresas } \\
\text { controlado } \\
\text { ras }\end{array}$ & $\begin{array}{c}\text { Estabelecim } \\
\text { entos filiais } \\
\text { controlados }\end{array}$ & $\begin{array}{c}\text { Distância média } \\
\text { das interações } \\
\text { entre município } \\
\text { e seus } \\
\text { congêneres (km) }\end{array}$ & $\begin{array}{c}\text { Assalariados } \\
\text { externos } \\
\text { comandados } \\
\text { pelo } \\
\text { município }\end{array}$ \\
\hline Agudo & 15 & 8 & 21 & 184 & 117 \\
\hline Boa Vista Do Incra & 1 & 1 & 1 & 61 & - \\
\hline Cacequi & 4 & 5 & 6 & 348 & 28 \\
\hline
\end{tabular}


SILVEIRA, FACCIN, KRUG

\begin{tabular}{|c|c|c|c|c|c|}
\hline Cachoeira Do Sul & 43 & 36 & 70 & 313 & 324 \\
\hline Cerro Branco & 2 & 1 & 2 & 284 & 3 \\
\hline Colorado & 3 & 3 & 3 & 179 & 4 \\
\hline Cruz Alta & 47 & 35 & 78 & 399 & 453 \\
\hline $\begin{array}{l}\text { Dilermando De } \\
\text { Aguiar }\end{array}$ & 1 & 1 & 1 & 508 & 2 \\
\hline Dona Francisca & 1 & 1 & 1 & 379 & 2 \\
\hline Faxinal Do Soturno & 7 & 11 & 14 & 308 & 34 \\
\hline Formigueiro & 3 & 5 & 5 & 374 & 1 \\
\hline Fortaleza Dos Valos & 3 & 3 & 4 & 263 & 13 \\
\hline Ibirubá & 34 & 24 & 72 & 216 & 2483 \\
\hline Itaara & 1 & 1 & 1 & 363 & 0 \\
\hline Jaguari & 7 & 7 & 9 & 288 & 18 \\
\hline Júlio De Castilhos & 9 & 9 & 21 & 342 & 46 \\
\hline Mata & 4 & 4 & 4 & 384 & 0 \\
\hline Não-Me-Toque & 28 & 19 & 78 & 236 & 1200 \\
\hline $\begin{array}{l}\text { Nova Esperança Do } \\
\text { Sul }\end{array}$ & 3 & 2 & 3 & 664 & 138 \\
\hline Nova Palma & 11 & 6 & 20 & 175 & 140 \\
\hline Novo Cabrais & 3 & 2 & 4 & 255 & 21 \\
\hline Paraíso Do Sul & 2 & 2 & 2 & 453 & 0 \\
\hline $\begin{array}{l}\text { Quinze De } \\
\text { Novembro }\end{array}$ & 4 & 4 & 7 & 381 & 30 \\
\hline Restinga Seca & 11 & 14 & 16 & 258 & 24 \\
\hline Saldanha Marinho & 2 & 2 & 2 & 216 & 3 \\
\hline Salto Do Jacuí & 3 & 4 & 4 & 223 & 8 \\
\hline $\begin{array}{l}\text { Santa Bárbara Do } \\
\text { Sul }\end{array}$ & 14 & 7 & 20 & 242 & 137 \\
\hline Santa Maria & 95 & 139 & 275 & 545 & 3782 \\
\hline Santiago & 26 & 40 & 73 & 275 & 549 \\
\hline $\begin{array}{l}\text { São Francisco De } \\
\text { Assis }\end{array}$ & 6 & 6 & 7 & 375 & 8 \\
\hline $\begin{array}{l}\text { São João Do } \\
\text { Polêsine }\end{array}$ & 2 & 2 & 2 & 448 & 0 \\
\hline $\begin{array}{l}\text { São Martinho Da } \\
\text { Serra }\end{array}$ & 1 & 1 & 1 & 414 & 0 \\
\hline São Pedro Do Sul & 6 & 12 & 12 & 297 & 27 \\
\hline São Sepé & 10 & 14 & 30 & 322 & 425 \\
\hline São Vicente Do Sul & 1 & 1 & 1 & 327 & 0 \\
\hline Selbach & 6 & 4 & 7 & 166 & 53 \\
\hline Tapera & 20 & 19 & 53 & 166 & 668 \\
\hline Toropi & 1 & 1 & 2 & 578 & 45 \\
\hline Tupanciretã & 13 & 10 & 20 & 223 & 55 \\
\hline Unistalda & 1 & 1 & 1 & 167 & 0 \\
\hline Vila Nova Do Sul & 4 & 3 & 4 & 283 & 4 \\
\hline
\end{tabular}

Fonte: IBGE (2014). Elaborada pela autora: Carolina Rezende Faccin.

A cidade de Santa Maria possuía em 2014, 139 empresas controladoras (sediadas no município), representando $38,29 \%$ das empresas controladoras com sede na região. Essas 139 empresas controlavam 275 estabelecimentos filiais distribuídos em 95 municípios, numa distância média entre sede e filial, de $545 \mathrm{~km}$. Portanto, sua centralidade econômica transcende o território regional constituído 
pelos 49 municípios que integram a região funcional 8 de planejamento, e alcança também municípios, em sua grande maioria, localizados em outras regiões do Estado do RS. Além disso, as empresas sediadas em Santa Maria, estabelecem relações de trabalho com um contingente de 3.782 trabalhadores, que são assalariados externos, pois estão empregados em suas filiais (IBGE, 2014).

Uma outra variável que permite analisar a capacidade de gestão do território pelas cidades médias se refere ao contingente de municípios e empresas atraídas, cujas sedes dessas últimas se localizam em outras cidades. Tais empresas atraídas atuam na cidade média através de suas filiais, por conta da dinamicidade e importância da sua economia urbana e do seu mercado consumidor, bem como de sua centralidade no contexto regional onde estão inseridas (Tabela 4).

Tabela 4 - Gestão territorial empresarial na RF 8 - 2014: Empresas atraídas, filiais e municípios atraídos

\begin{tabular}{|c|c|c|c|c|}
\hline Nome do município & $\begin{array}{l}\text { Municípios } \\
\text { atraídos }\end{array}$ & $\begin{array}{l}\text { Estabeleciment } \\
\text { os-filiais } \\
\text { atraídos }\end{array}$ & $\begin{array}{l}\text { Empresa } \\
\mathrm{s} \text { atraídas }\end{array}$ & $\begin{array}{l}\text { Percentual sobre o total de } \\
\text { assalariados que se } \\
\text { reportam a empresas-sede } \\
\text { fora dos limites municipais }\end{array}$ \\
\hline Agudo & 22 & 40 & 39 & 20,39 \\
\hline Boa Vista Do Cadeado & - & - & - & 61,76 \\
\hline Boa Vista Do Incra & 6 & 9 & 7 & 71,96 \\
\hline Cacequi & 14 & 22 & 20 & 24,06 \\
\hline Cachoeira Do Sul & 41 & 140 & 103 & 19,37 \\
\hline Capão Do Cipó & & & & 67,61 \\
\hline Cerro Branco & 6 & 7 & 7 & 29,46 \\
\hline Colorado & 9 & 19 & 15 & 70,45 \\
\hline Cruz Alta & 59 & 146 & 121 & 36,24 \\
\hline Dilermando De Aguiar & 3 & 3 & 3 & 55 \\
\hline Dona Francisca & 4 & 9 & 7 & 43,81 \\
\hline Faxinal Do Soturno & 11 & 15 & 15 & 20,72 \\
\hline Formigueiro & 8 & 17 & 14 & 57,05 \\
\hline Fortaleza Dos Valos & 7 & 18 & 11 & 63,95 \\
\hline Ibirubá & 31 & 65 & 56 & 5,49 \\
\hline Itaara & 6 & 8 & 8 & 35,31 \\
\hline Ivorá & - & - & - & 26,79 \\
\hline Jaguari & 13 & 22 & 22 & 5,74 \\
\hline Jari & - & - & - & 42,5 \\
\hline Júlio De Castilhos & 23 & 51 & 44 & 25,93 \\
\hline Lagoa Dos Três Cantos & - & - & - & 51,43 \\
\hline Mata & 3 & 6 & 6 & 11 \\
\hline Não-Me-Toque & 19 & 37 & 36 & 5,16 \\
\hline Nova Esperança Do Sul & 8 & 17 & 16 & 5,07 \\
\hline Nova Palma & 3 & 6 & 6 & 6,01 \\
\hline Novo Cabrais & 5 & 5 & 5 & 10,71 \\
\hline Paraíso Do Sul & 6 & 10 & 10 & 7,85 \\
\hline Pinhal Grande & - & - & - & 41,6 \\
\hline
\end{tabular}




\begin{tabular}{lcccc}
\hline Quevedos & - & - & - & 29,41 \\
\hline Quinze De Novembro & 4 & 13 & 10 & 60,08 \\
\hline Restinga Seca & 23 & 34 & 31 & 21,28 \\
\hline Saldanha Marinho & 8 & 14 & 12 & 80,71 \\
\hline Salto Do Jacuí & 15 & 29 & 25 & 45,41 \\
\hline Santa Bárbara Do Sul & 17 & 38 & 30 & 46,02 \\
\hline Santa Maria & 94 & 431 & 293 & 15,91 \\
\hline Santiago & 33 & 80 & 66 & 20,81 \\
\hline São Francisco De Assis & 18 & 32 & 28 & 38,09 \\
\hline São João Do Polêsine & 7 & 10 & 7 & 28,96 \\
\hline São Martinho Da Serra & 6 & 7 & 7 & 58,06 \\
\hline São Pedro Do Sul & 17 & 31 & 27 & 15,76 \\
\hline São Sepé & 21 & 43 & 39 & 31,93 \\
\hline São Vicente Do Sul & 13 & 23 & 23 & 34,51 \\
\hline Selbach & 10 & 23 & 14 & 9,4 \\
\hline Silveira Martins & - & - & - & 18,09 \\
\hline Tapera & 18 & 31 & 28 & 11,76 \\
\hline Toropi & 3 & 4 & 4 & 19,72 \\
\hline Tupanciretã & 23 & 47 & 41 & 57,55 \\
\hline Unistalda & 3 & 5 & 5 &
\end{tabular}

Fonte: IBGE (2014). Elaborada pela autora: Carolina Rezende Faccin.

Nesse aspecto, destaca-se a capacidade de atração empresarial da cidade de Santa Maria Sul que em 2014 atraiu 431 estabelecimentos filiais de 293 empresas externas, com sede em 94 municípios. Santa Maria, atraiu 23\% de todas as empresas atraídas pelas demais cidades da região. Além disso, do total dos assalariados do município, $15,91 \%$ estão subordinados a empresas sede, localizadas fora dos limites municipais. Tais dados evidenciam importantes fluxos de capital externos e que se destinam para Santa Maria seja através dos investimentos na abertura e manutenção de estabelecimentos filiais, ou através do pagamento de salários dos empregados nesses estabelecimentos filiais (IBGE, 2014).

Além de atrair empresas cujas sedes estão localizadas na região, a cidade de Santa Maria também tem atraído filiais de bancos, empresas de comércio e serviços e de grandes redes estaduais, nacionais e transnacionais que atuam no ramo da alimentação e lojas de departamento, como Carrefour, Mcdonalds, Subway, Walmart, Lojas Renner, Lojas Americanas, Magazine Luiza, Casas Bahia, Ponto Frio, Lojas Colombo, Benoit, Pompéia, Quero-Quero, TaQi, entre outras. Instaladas na área central da cidade e em seus quatro Shoppings Centers junto às vias de ligação intrarregional, essas sucursais de empresas forâneas, potencializam e ampliam a abrangência territorial da oferta de consumo especializado dessa cidade média. 
Por fim, cabe também destacar a importância da intensidade das ligações econômicas entre as empresas para a análise dos padrões das redes de gestão territorial, bem como para gerar uma dada medida da centralidade urbana no espaço regional. Assim, a intensidade das ligações resulta do somatório das interações entre as empresas sedes e suas filiais, considerando a capacidade de cada município em abrigar empresas-sedes locais que se articulam com sucursais externas ao seu território e, ao mesmo tempo, levando em conta a presença de filiais atraídas para o seu território, sendo estas geridas por empresas-sede instaladas fora dos seus limites (IBGE, 2014).

Nesse aspecto, a cidade de Santa Maria apresenta uma intensidade de 1.138 ligações entre empresas, somadas aqui tanto as relações existentes entre as empresas que nela tem sede e suas filiais externas, quanto as relações estabelecidas com as empresas externas, atraídas por essa cidade, através da atração de suas filiais. Esse expressivo desempenho além de representar $27 \%$ do total das ligações existentes nos 49 municípios que integram a região, também traduz a forte centralidade que essa cidade média possui na região central do Rio Grande do Sul.

\section{Considerações Finais}

O contexto atual em que vivemos no Brasil, de intensa urbanização, e de ampla e crescente mobilidade de fluxos diversos no território, requer uma análise mais detalhada sobre a tipologia, o conteúdo e reflexos desses fluxos na organização e na gestão do território, e de como as cidades médias têm participado desse processo, notadamente na escala regional do território brasileiro.

Entendemos que tanto o Estado quanto o Mercado são duas instituições com grande poder de estruturação e gestão territorial, por meio de suas ações e dos fluxos que geram e atraem através de suas organizações. Assim, de um lado, temos a gestão pública do território realizada pelo Estado e seus organismos públicos visando o atendimento da população, o provimento da infraestrutura, o levantamento de dados e informações e o recolhimento de impostos. De outro lado, temos a gestão privada ou empresarial através das relações que as empresas privadas estabelecem no mercado, com suas ações, articulações e estratégias particulares no território, visando a reprodução do capital. As cidades médias desempenham papel destacado nesse processo, ao participarem efetivamente da intermediação desses 
fluxos, e ao servirem de suporte e condição para a gestão territorial pública e empresarial nos espaços regionais.

A análise dos dados permitiu verificar o destacado papel de comando e de intermediação que a cidade média de Santa Maria apresenta na gestão do território na Região Central do Rio Grande do Sul, através dos fluxos de gestão pública e empresarial. Em relação a gestão pública do território, os dados sobre os fluxos e ligações relativas a gestão pública federal no território, através da oferta descentralizada de serviços públicos relacionados à Receita Federal, Polícia Federal, Previdência Social e Justiça Federal, revelaram inicialmente a grande centralidade da cidade de Santa Maria no território da Região Funcional 8 de Planejamento. Bem como, a também importante centralidade dessa cidade nessa região, pois é nela que estão localizadas as repartições desses órgãos públicos que atuam na região. Quanto à gestão empresarial do território os dados mostraram que a cidade de Santa Maria apresenta os maiores níveis de intensidade nas ligações econômicas na região, advindas do somatório das relações entre as empresas que essa cidade sedia e as suas filiais, localizadas em municípios externos à região. Também, das ligações que essa cidade promove através da atração de empresas externas, através da instalação de filiais e subsidiárias. A importância econômica que a agroindústria da soja e do arroz, bem como a extração mineral de areia possui na economia urbana e regional, acrescida de uma crescente e diversificada economia de comércio e serviços, sobretudo na área do comércio atacadista e varejista, alimentação, educação e saúde, revela a centralidade econômica dessa cidade no contexto regional. Os dados sobre assalariamento externo, também evidenciam o relevante poder de comando territorial que a cidade de Santa Maria possui, extravasando a região de influência imediata e alcançando outras regiões vizinhas, no Rio Grande do Sul.

A cidade média de Santa Maria por sediar estruturas descentralizadas das instituições públicas federais que atuam na região, bem como por sediar empresas locais e regionais e por atrair filiais de empresas externas à região, possui poder de comando e decisão sobre o conjunto da rede urbana regional. Por conta disso, influencia ativamente a dinâmica de desenvolvimento territorial na escala da Região Funcional 8 de Planejamento, bem como participa de modo destacado na dinâmica de desenvolvimento territorial da região Central do Rio Grande do Sul, pela sua situação central no território gaúcho, bem como pela sua localização junto às 
principais rodovias que conectam e integram as parcelas oeste-leste e norte-sul do território estadual.

Os dados e resultados apresentados nesse estudo de caso buscam contribuir para o aprofundamento e aplicação das reflexões teóricas desenvolvidas seminalmente por Corrêa $(1989 ; 1996)$ e para avançar a análise dos dados secundários levantados pelo $\operatorname{IBGE}(2014 ; 2018)$ sobre a temática da gestão territorial das cidades, em especial das cidades médias brasileiras.

A função de gestão territorial exercida pelas cidades médias nos espaços geográficos onde estão localizadas e nas regiões de influência onde exercem sua centralidade demonstra a importância de considerarmos o papel da gestão pública e da gestão privada nas relações e interações que tais cidades estabelecem no âmbito da rede urbana brasileira.

As características socioespaciais, o grau de intensidade, e a abrangência espacial como cada cidade média exerce sua centralidade e estabelece tais relações, nas diferentes regiões do território brasileiro, estão condicionadas, de um lado pela sua dinâmica de urbanização e estrutura econômica, e de outro lado pelo modo particular como o Estado, através das instituições públicas federais e estaduais, e o Mercado através das organizações empresariais, estão organizados nessas cidades e nessas regiões. As relações e os fluxos de gestão territorial pública e privada estão também condicionadas pela divisão territorial do trabalho existente em cada região e pelo papel polarizador e pelas funções que cada uma dessas cidades médias desempenha nas redes urbanas regionais e brasileira,

Tendo isso presente, e diante da diversidade territorial e da desigualdade regional brasileira existente nas escalas nacional e subnacional, entendemos que é de fundamental importância ampliarmos os estudos de caso sobre a gestão territorial das cidades médias brasileiras de modo a melhor compreender as particularidades, as semelhanças e as especificidades como esse processo ocorre nas diferentes regiões do território brasileiro. Esse esforço de pesquisa igualmente será importante para aperfeiçoar ou mesmo melhor fundamentar as políticas públicas de planejamento e de desenvolvimento regional.

\section{REFERÊNCIAS}

BELLET. C.; OLAZABAL, E. Formas de crecimiento urbano de las ciudades medias españolas en las últimas décadas. Terr@Plural, Ponta Grossa, v. 14, ed. 1, p. 1-19, 2020. 
BELLET, C.; MELAZZO, E. S.; SPOSITO, M. E. B.; LLOP, J. M. (Org.). Urbanización, producción y consumo en ciudades medias/intermedias. Presidente Prudente:

Universidade Estadual Paulista; Lleida: Edicions de la Universitat de Lleida, 2015. Disponível em:

$<$ https://www.researchgate.net/publication/281290001 Urbanizacion produccion y consum o en ciudades mediasintermedias $>$. Acesso em 14 fev. 2021.

CORRÊA, R. L. Caminhos paralelos e entrecruzados. São Paulo: Ed. Unesp, 2018.

CORRÊA, R. L. Os centros de gestão do território: uma nota. Revista Território, v. 1, ed. 1, p. 23-30, 1996.

CORRÊA, R. L. Corporação, Práticas Espaciais e Gestão do Território. Anuário do Instituto de Geociências, v. 15, ed. 1, p. 35-41, 1992.

CORRÊA, R. L. Os centros de gestão e seu estudo. Revista Brasileira de Geografia, Rio de Janeiro, v. 51, ed. 4, p. 109-119, 1989. Disponível em:

$<$ http://biblioteca.ibge.gov.br/visualizacao/periodicos/115/rbg 1989 v51 n4.pdf >. Acesso em 14 fev. 2021.

COSTA, E. M. As pequenas e médias cidades portuguesas - dinámicas demográficas e funcionais nos últimos quarenta anos. pp. 258-288. In: MATURANA, F.; SPOSITO, M.E.B.; BELLET, C.; HENRÍQUEZ, C.; ARENAS, F. (Org.) Sistemas urbanos y ciudades medias en Iberoamérica. Santiago de Chile: GEOlibros, 2017. Disponível em:

<http://geografia.uc.cl/images/GeoLibros/GEOlibros CIUDADES\%20MEDIAS.pdf>. Acesso em 14 fev. 2021.

DEMAZIÈRE, C. O lugar das cidades pequenas e médias na investigação sobre o urbanismo. Um ponto de vista francês. pp. 79-98. In: SILVA, W. R.; SPOSITO, M. E. B. (Org.) Perspectivas da urbanização: reestruturação urbana e das cidades. Rio de Janeiro: Ed. Consequência, 2017.

IGLESIAS, B. M. Las ciudades intermedias en la integración territorial del Sur Global. Revista CIDOB d'Afers Internacionals, v. 114, p. 109-132, 2016. Disponível em: $<$ https://core.ac.uk/download/pdf/83002741.pdf>. Acesso em 14 fev. 2021.

INSTITUTO BRASILEIRO DE GEOGRAFIA E ESTATÍSTICA (IBGE). Região de Influência das Cidades - REGIC 2018. Rio de Janeiro, IBGE, 2020. Disponível em: $<$ https://biblioteca.ibge.gov.br/index.php/biblioteca-catalogo?view=detalhes\&id=2101728>. Acesso em 14 fev. 2021.

INSTITUTO BRASILEIRO DE GEOGRAFIA E ESTATÍSTICA (IBGE). Cidades e Estados. Rio de Janeiro, IBGE, 2020. Disponível em: <https://www.ibge.gov.br/cidades-eestados/rs/santa-maria.html>. Acesso em 14 fev. 2021.

INSTITUTO BRASILEIRO DE GEOGRAFIA E ESTATÍSTICA (IBGE). Pesquisa de Informações Básicas Municipais - MUNIC. Rio de Janeiro: IBGE, 2018. Disponível em: $<$ www.ibge.gov.br/estatisticas/sociais/saude/10586-pesquisa-de-informacoes-basicas$\underline{\text { municipais.html }}$

INSTITUTO BRASILEIRO DE GEOGRAFIA E ESTATÍSTICA (IBGE). Grade estatística. Rio de Janeiro: IBGE, 2016. Disponível em:

<https://portaldemapas.ibge.gov.br/portal.php\#homepage>. Acesso em 14 fev. 2021.

INSTITUTO BRASILEIRO DE GEOGRAFIA E ESTATÍSTICA (IBGE). Arranjos populacionais e Concentrações Urbanas do Brasil. Rio de Janeiro: IBGE, 2015. Disponível em: <www.ibge.gov.br/apps/arranjos populacionais/2015/>. Acesso em $14 \mathrm{fev}$. 2021.

INSTITUTO BRASILEIRO DE GEOGRAFIA E ESTATÍSTICA (IBGE). Centros de Gestão do Território. Rio de Janeiro: IBGE, 2014. Disponível em: 
<www.ibge.gov.br/home/geociencias/geografia/redes fluxos/gestao do territorio 2014/>. Acesso em 14 fev. 2021.

INSTITUTO BRASILEIRO DE GEOGRAFIA E ESTATÍSTICA (IBGE). Divisão Urbanoregional. Rio de janeiro: IBGE, 2013. Disponível em:

$<$ https://www.ibge.gov.br/geociencias/cartas-e-mapas/redes-geograficas/15777-divisaourbano-regional.html?=\&t=sobre $>$. Acesso em 14 fev. 2021.

INSTITUTO BRASILEIRO DE GEOGRAFIA E ESTATÍSTICA (IBGE). Censo demográfico. Rio de Janeiro: IBGE, 2010. Disponível em:

<https://censo2010.ibge.gov.br/resultados.html>. Acesso em 14 fev. 2021.

INSTITUTO BRASILEIRO DE GEOGRAFIA E ESTATÍSTICA (IBGE). Região de Influência das Cidades - REGIC 2007. Rio de Janeiro, IBGE, 2008. Disponível em:

$<$ www.ibge.gov.br/geociencias/cartas-e-mapas/redes-geograficas/15798-regioes-deinfluencia-das-cidades.html>. Acesso em 14 fev. 2021.

INFRAESTRUTURA ESTADUAL DE DADOS ESPACIAIS (IEDE). Estabelecimentos de gestão estadual. 2019. Disponível em: <https://iede.rs.gov.br/>. Acesso em 14 fev. 2021.

LAN, D.; MIGUELTORENA, A. Aportes para el estudio de ciudades intermedias de Argentina. p.16-43. In: MATURANA, F.; SPOSITO, M.E.B.; BELLET, C.; HENRÍQUEZ, C.; ARENAS, F. (Org.) Sistemas urbanos y ciudades medias en Iberoamérica. Santiago de Chile: GEOlibros, 2017. Disponível em:

<http://geografia.uc.cl/images/GeoLibros/GEOlibros CIUDADES\%20MEDIAS.pdf>. Acesso em 14 fev. 2021.

LLOP, J. M.; USÓN, E. (Org). Ciudades Intermedias. Dimensiones y definiciones. Lleida: Editorial Milenio, 2012.

MARTÍNEZ NAVARRO, J. M.; GARCÍA GONZÁLEZ, J. A.; ESCUDERO GÓMEZ, L. A. Las ciudades medias de España y sus coronas en el siglo XXI (2000-2017): dinámica demográfica y desarrollo inmobiliario. URBE - Revista Brasileira de Gestão Urbana, v. 12, ed. e20190202, 2020. DOI: https://doi.org/10.1590/2175-3369.012.e20190202

MARQUES, P. W. T.; RIBEIRO, M. A. Geografia e Estado - Organização territorial e a criação de centralidades a partir das instituições públicas. Revista Política e Planejamento Regional, Rio de Janeiro, v. 6, ed. 3, p. 271-286, 2019.

MOTTA, D.; MATA, D. Crescimento das cidades médias. Boletim Regional Urbano. Brasília: IPEA, 2008. E-book. Disponível em:

<http://repositorio.ipea.gov.br/handle/11058/5525>. Acesso em 14 fev. 2021.

NEAL, Z. P. The Connected City: How Networks are shaping the modern metrópolis. New York: Routledge, 2013.

OLIVEIRA, H. C. M.; SOARES, B. Cidade média: apontamentos metodológicos e tipologia. Revista Caminhos de Geografía, v. 15, ed. 52, p. 119-133, 2014.

ORGANIZAÇÃO DAS NAÇÕES UNIDAS (ONU). La situación demográfica en el mundo 2014. Informe. New York: Nações Unidas, 2014.

RELAÇÃO ANUAL DE INFORMAÇÕES SOCIAIS (RAIS). Número de empregados da Indústria da Transformação. 2010. Disponível em:

$<$ http://bi.mte.gov.br/bgcaged/caged rais vinculo id/login.php>. Acesso em 14 fev. 2021.

ROBERTS, B. H. Managing Systems of Secondary Cities: Policy Responses in International Development. Bruselles: Ed. Cities Alliance, 2014. Disponível em: $<$ https://www.citiesalliance.org/sites/default/files/1d\%20(i)\%20$\% 20$ Managing\%20Systems\%200f\%20Secondary\%20Cities\%20Book low res.pdf>. Acesso em 14 fev. 2021. 
SANTOS, M.; SILVEIRA, M. L. O Brasil: Sociedade e Território no começo do século XXI. Rio de Janeiro: Ed. Record, 2001.

SECRETARIA DE PLANEJAMENTO, ORÇAMENTO E GESTÃO (SEPLAG);

DEPARTAMENTO DE PLANEJAMENTO GOVERNAMENTAL (DEPLAN). Perfis

Socioeconômicos Regiões Funcionais de Planejamento. Porto Alegre:

SEPLAG/DEPLAN, 2015. Disponível em:

$<$ https://planejamento.rs.gov.br/upload/arquivos/201512/15134058-20150319163519perfis-

todos.pdf>. Acesso em 14 fev. 2021.

SECRETARIA DE PLANEJAMENTO, GOVERNANÇA E GESTÃo (SPGG). Plano

Estratégico de Desenvolvimento Regional do COREDE Central 2015-2030. Porto Alegre: SPPG, 2017. Disponível em:

<https://governanca.rs.gov.br/upload/arquivos/201710/09144203-plano-central.pdf $>$. Acesso em 14 fev. 2021.

SCHERER, C. E. M.; AMARAL, P. V. M. O espaço e o lugar das cidades médias na rede urbana brasileira. Revista Brasileira de Estudos Urbanos e Regionais, Rio de Janeiro, v. 22, ed. e202001, p. 1-25, 2020.

SERVILLO, L.; ATKINSON, R.; SMITH I.; RUSSO, A.; SÝKORA L.; DEMAZIÈRE, C.; HAMDOUCH, A. Town: Small and medium sized towns in their functional territorial context - Final Report. Luxembourg: ESPON, 2004.

SILVEIRA, R. L. L.; BRANDT, G. B.; FACCIN, C. R.; SILVEIRA, L. L.; KUMMER, D. C. Policentrismo, Áreas Urbanas Funcionais (FUAs) e Dinâmica Territorial: Um estudo exploratório desde a região do Vale do Rio Pardo - RS - Brasil. Redes, Santa Cruz do Sul, v. 22, ed. 1, p. 184-217, 2017.

SPOSITO, M. E. B. Cidade Média. p. 39-47. In: SPOSITO, E. S. Glossário de Geografia Humana e Econômica. São Paulo. Editora UNESP, 2018.

SPOSITO, M. E. B. (Org). Cidades Médias: Espaços em Transição. São Paulo: Editora Expressão Popular, 2007.

SPOSITO, M. E. B.; SILVA, W. R. da. Perspectivas da urbanização: Reestruturação urbana e das cidades. Rio de Janeiro: Editora Consequência, 2017.

STAMM, C.; WADI, Y. M.; STADUTO, J. A. R. São as cidades médias responsáveis pelo espraiamento espacial da riqueza nacional?. Redes, Santa Cruz do Sul, v. 15, ed. 2, p. 6691, 2010. DOI: https://doi.org/10.17058/redes.v15i2.1019

UNIVERSIDADE FEDERAL DE SANTA MARIA - UFSM. UFSM em números: dados referentes ao período $1^{\circ}$ Semestre de 2020. 2020. Disponível em:

$<$ https://portal.ufsm.br/ufsm-em-numeros/publico/index.html>. Acesso em 14 fev. 2021.

VARGAS, E. C. Comércio, serviços e cidade: subsídios para gestão urbana. Revista

Brasileira de Estudos Urbanos e Regionais, v. 22, ed. e202010pt, p. 1-26, 2020.

\section{NOTAS DE AUTOR}

\section{CONTRIBUIÇÃO DE AUTORIA}

Rogério Leandro Lima da Silveira - Concepção. Análise de dados, Elaboração do manuscrito, revisão e aprovação da versão final do trabalho.

Carolina Rezende Faccin - Coleta de dados, análise de dados, elaboração das figuras, participação ativa da discussão dos resultados, formatação e revisão.

Débora Frantz Krug - Coleta de dados; análise inicial dos dados, elaboração dos mapas temáticos, participação ativa da discussão dos resultados. 
FINANCIAMENTO

Conselho Nacional de Pesquisa e Desenvolvimento - CNPq

CONSENTIMENTO DE USO DE IMAGEM

Não se aplica.

APROVAÇÃO DE COMITÊ DE ÉTICA EM PESQUISA

Não se aplica.

CONFLITO DE INTERESSES

Não há conflitos de interesses.

\section{LICENÇA DE USO}

Este artigo está licenciado sob a Licença Creative Commons CC-BY. Com essa licença você pode compartilhar, adaptar, criar para qualquer fim, desde que atribua a autoria da obra.

\section{HISTÓRICO}

Recebido em: 16-02-2021

Aprovado em: 15-11-2021 